\title{
Affective and Stress Consequences of Cyberbullying
}

\author{
Ashraf Alhujailli ${ }^{1,2, *}{ }^{\circ}$, Waldemar Karwowski ${ }^{1}\left(\mathbb{D}\right.$, Thomas T.H. Wan ${ }^{3}$ and Peter Hancock ${ }^{1,4}$ \\ 1 Department of Industrial Engineering \& Management Systems, University of Central Florida, Orlando, \\ FL 32816, USA; wkar@ucf.edu (W.K.); Peter.Hancock@ucf.edu (P.H.) \\ 2 Department of Management Sciences and Industrial Technology, Yanbu University College, \\ Industrial Yanbu 46455, Saudi Arabia \\ 3 Department of Health Management and Informatics, University of Central Florida, Orlando, FL 32816, USA; \\ Thomas.Wan@ucf.edu \\ 4 Department of Psychology, University of Central Florida, Orlando, FL 32816, USA \\ * Correspondence: ashraf@knights.ucf.edu; Tel.: +966-5550-48618
}

Received: 1 August 2020; Accepted: 14 September 2020; Published: 17 September 2020

\begin{abstract}
The primary objective of this study was to investigate the effects of cyberbullying through social exclusion and verbal harassment on emotional, stress, and coping responses. Twenty-nine undergraduate students (16 females aged $18.25 \pm 0.58$ years and 13 males aged $18.46 \pm 1.13$ years) volunteered for the study. All volunteers participated in two experiments that stimulated cyberbullying through social exclusion or verbal harassment. In the first experiment, the effects of cyberbullying through social exclusion were investigated using a virtual ball-tossing game known as Cyberball. In the second experiment, the influence of cyberbullying through verbal harassment was tested using a hypothetical scenario together with reading of online comments. Emotional, stress, and coping responses were measured via the Positive Affect and Negative Affect Scale, the Dundee Stress State Questionnaire, and the Coping Inventory for Task Stress, respectively. The results demonstrated that social exclusion and verbal harassment induced a negative emotional state. We also found that verbal harassment through the use of impolite language increased engagement, and increased worry compared with social exclusion effects.
\end{abstract}

Keywords: cyberbullying; emotions; bullying; social ostracism; stress; social exclusions; harassment

\section{Introduction}

The first published study on bullying phenomena was written by Burk [1]. However, this subject matter was not systematically studied until the 1970s by Olweus [2]. Since then, numerous studies have examined bullying from different perspectives. Research on bullying has investigated settings such as schools and workplaces [3,4]. More recently, the term bullying has been expanded to include a new type known as cyberbullying, which is conducted via the Internet. Navarro et al. [5] have defined cyberbullying and bullying as "aggressive conduct whose objective is to harm another person, which most certainly refers to violent social behavior." Willard [6] has suggested the term "digital aggression" [7]. Hazelwood and Koon-Magnin [8] and Moy [9] have indicated that the National Conference of State Legislatures makes a distinction between the terms cyberbullying and cyberharassment. Their differences mainly pertain to the age of the cyberbullied individual. Bullying can be classified as an indirect act in which the bullied individual is not present or as a direct act involving face-to-face contact [10]. Researchers have raised concerns regarding whether bullying is considered a form of aggression. Berger [10] has highlighted that "not all aggression is bullying, but bullying is always aggression, comprising hurtful and hostile behavior" [11]. Johnson [12] has considered cyberbullying as "indirect or relational aggression" that damages social relationships. 
Some authors have added anonymity and publicity as features of cyberbullying [13]. However, the term cyberbullying has frequently been used in the published literature [3].

Anonymity on the Internet can facilitate cyberbullying attacks. The target for such attacks can be any individual (e.g., one who is popular, famous, physically weak, or strong) [14,15]. This action can be repetitive and can create a sense of fear in cyberbullying targets [8]. A larger audience and unrestricted accessibility to victims makes cyberbullying more destructive than traditional bullying $[7,10,12,16,17]$.

Willard [6] has defined eight common types of cyberbullying: Exclusion, harassment, flaming, cyberstalking, denigration, impersonation, outing, and trickery. Li [18] has categorized cyberbullying into seven types: Flaming, masquerading, cyberstalking, denigration, online harassment, outing, and exclusion. According to Dooley et al. [19], there are four types of cyberbullying attacks: (1) Social, (2) psychological, (3) physical, and (4) relational [20]. Some of the cyberbullying attacks can take the form of making jokes about someone or a group, making mean or aggressive remarks, or spreading rumors and lies [12]. Cyberbullying exerts negative physical and emotional effects on victims and has been found contribute to increasing rates of attempted suicide [21]. Worry, fear, depression, terror, and nervousness are among the psychological problems that cyberbullied individuals might feel [8]. Wang et al. [22] has shown that cyberbullying indirectly affects depression in bullied individuals via social anxiety. Individuals who are bullied might feel negative psychological consequences, such as depression or lower self-esteem [23]. Furthermore, Jawaid et al. [24] have classified cyberbullying as a social vulnerability [25]. This social vulnerability causes the exclusion of individuals who could otherwise be productive members of society [24]. According to Ybarra and Mitchell [26], acts of cyberbullying increase with age. Cyberbullying acts can be driven by revenge [27] or many other reasons [28].

Sticca and Perren [17] have described publicity as the size of the audience communicating via social media, either privately or publicly. They have indicated that publicity attacks in cyberbullying can take a private form (e.g., email) or a public form (e.g., Twitter or Facebook). Dooley et al. [29] considers publicity to be a factor in cyberbullying. Public cyberbullying has been found to be more harmful than private cyberbullying [17,30]. Slonje and Smith [16] and colleagues have hypothesized that "as the number of people participating online increases, the severity of cyberbullying increases." However, Menesini et al., [13] have used a different experimental approach and found that publicity is irrelevant to cyberbullying. According to Vasquez and colleagues, public verbal harassment has a greater negative emotional impact than private bullying [31]. Otten and colleagues have attributed this aspect to the "larger emotional processing in public encounters," which produces an increase in brain activity [32].

Another form of private bullying is a silent treatment, a "relational aggression" performed by a partner [33,34]. This is another version of private social exclusion, wherein a partner is intentionally ignored and rejected [35]. For example, this process can occur when an individual sends many text messages to someone and does not receive any response [35]. According to a survey by Faulkner et al. [36], almost three in four Americans have encountered silent treatments. As reviewed by Alhujailli and Karwowski [37], there have been relatively few studies comparing the effects of verbal harassment and social exclusion. Although, bullying acts across cultures are common, social exclusion form is a more common form in collectivist culture [38].

Recent meta-analyses by Guo [39] and Kowalski, Giumetti, Schroeder, and Lattanner [20] have shown that few studies have used experimental settings. Guo [39] has investigated bullying behaviors, such as harassment, threatening, and social exclusion. Another meta-analysis by [40] has analyzed 120 studies using Cyberball games to study social exclusion. Those studies did not examine other types of cyberbullying, such as verbal harassment. We were unable to find studies indicating whether "verbal harassment" or "social exclusion" is more severe. Therefore, the aim of this study was to advance knowledge about cyberbullying and to provide an understanding of the immediate reactions toward verbal harassment and social exclusion. In terms of gender reactions, Romero-Canyas and Downey [41] and Reijntjes et al. [42] have found that females are more receptive than males to private 
rejection. However, Steele [43] has found no significant difference in reactions toward bullying between male and female participants.

\subsection{Theoretical Background}

According to Social Information Processing theory, people engaging in computer-mediated communication might use a virtual communication system (e.g., social media) to engage in social interactions that are equivalent to face-to-face interactions [44]. Thus, nonverbal cues in physically present interactions have a different form (e.g., unlimited time accessibility) from that of computer-mediated communication. Here, we examined the theoretical aspects relevant to cyberbullying, particularly in terms of affective and stress responses.

\subsection{Emotional Responses}

People recognize happiness, sadness, anger, and joy as emotions. However, the definition of emotion has been subject to debate. Kleinginna and Kleinginna [45] have identified as many as 92 definitions of emotion in the literature. However, Brave and Nass [46] have indicated that "researchers did agree on two aspects of emotion: (1) Emotion is a natural reaction to an event associated with the goals, needs, and concerns of an individual; and (2) emotion involves affective, behavioral, physiological, and cognitive components." However, dimensional theories classify emotions on a multidimensional basis. For example, the Positive Affect-Negative Affect model (PANA) developed by Watson and Clark [47] categorizes emotions in two independent dimensions, where the Y-axis represents positive affect (PA), and the $\mathrm{X}$-axis represents negative affect (NA). Though the acronym PANA might mistakenly be understood as representing two opposite affective states, they are two independent dimensional metrics measured simultaneously. PA reflects "the degree to which an individual feels positively active and enthusiastic," whereas NA reflects "the degree to which an individual feels aversive" [47]. A high level of PA suggests an enjoyable interaction. NA is generally correlated with unpleasant engagement and distress, both of which reflect aversive feelings, such as disgust, anger, nervousness, or guilt. A low NA level causes a state of "serenity and calmness" [47,48]. According to Hinduja and Patchin [49], cyberbullying promotes negative emotional impacts. These impacts vary not only between individuals but also between the type of cyberbullying experienced [13]. In the present study, emotional responses were built on the basis of the dimensional basis of PA and NA. Thus, a low level of PA and a high level of NA were expected to be observed during negative social interactions (e.g., cyberbullying) [50,51].

\subsection{Cyberbullying and Stress}

The transactional model of stress and coping theory states that an individualistic appraisal of a stressful event is regulated by how people cope with the level of induced stress [52]. Cyberbullying has been demonstrated to impose stress [53]. However, much of cyberbullying research has used the Transactional model of stress and coping [54]. Williams and Carter-Sowell [55] have indicated that cyberbullying poses a threat to belonging, which is one of the basic human needs that may lead to stress.

Repetitive negative stressors over time can create emotional distress and degrade performance $[56,57]$. Contrarily, social support can decrease negative feelings about stressful situations [58,59]. Stress has been found to reduce performance [60], and cyberbullying induces immediate emotional responses as well as subsequent stress reactions. Repetitive cyberbullying events cause instant emotional responses and chronic effects. Therefore, cyberbullying can exert both chronic (longer-lasting) and acute (short-term) effects. Matthews et al. [61] have linked stress factors to Lazarus' Transactional Model. Hobfoll [62] has indicated that stress is a result of how situations are appraised. 


\subsection{Cyberbullying and Coping}

Lazarus and Folkman [52] have defined coping as the "behavioral and cognitive capabilities an individual deploys to tolerate and control stressful events". Judgment and evaluation are two forms of cognitive appraisal that are correlated with coping demands, both of which are effective factors to predict coping strategy $[63,64]$.

Individual differences play an important role in the coping strategy used by individuals faced with stressors [65]. Individuals reported to use emotion-focused coping are inclined to be more affected by stressful events than those who use problem-focused coping [66]. Völlink, Bolman Catherine, Dehue, and Jacobs Niels [54] have claimed that a problem-solving strategy is better than an avoidance strategy. The group has also indicated that during cyberbullying, emotion-focused coping is correlated with health complaints [54]. Lodge and Frydenberg [67] have observed that female teenagers who use avoidance coping tend to have low self-esteem.

The self-perception of a cyberbullying threat and the evaluation of which coping strategy to use is called coping appraisal [68]. Threat appraisals can have different reactions, including the threat of harm, the threat of loss and threat to the self $[64,69]$. Chan and Wong [70] indicated that younger adolescent male are more likely to deploy an avoidance coping to deal with being cyberbullied. In summary, the coping style adopted is based on individualistic differences and how individuals appraise each threat differently.

\subsection{Types of Cyberbullying}

\subsubsection{Social Exclusion}

Social exclusion occurs in public or private (e.g., silent treatment). Social exclusion is common across cultures and age groups [33] and has been reported to violate "the need-threat theory" [71]. The four elements of basic human needs, (1) belonging, (2) self-esteem, (3) control, and (4) meaningful existence $[35,36,72,73]$, are relevant in cyberbullying events. Cyberbullied individuals score lower than non-cyberbullied individuals in self-esteem after being socially excluded [74]. Eisenberger [75] has indicated that social inclusion is "pre-wired in our brain" and that an incident of social exclusion leads to "social pain." When we sense exclusion, an alarm is triggered that is similar to physical pain, except that the reaction is acquired through experience [73]. Williams et al. [76] have conducted an experiment called "cyber-ostracism," in which they developed a simulated chat room to perform social exclusion and found that cyber-ostracized participants reported negative emotional impacts.

\subsubsection{Verbal Harassment}

Verbal harassment, in the present context, is text-based bullying that occurs during electronic social interactions. It is the most common form of bullying [77]. Individuals bullied via both texting and traditional bullying are more depressed than those subjected to only traditional bullying [78]. Willard [6] has indicated that "harassment" is equivalent to direct bullying. Deficits in executive functioning have been found to be correlated with bullying behavior in youth engaging in antisocial and aggressive behaviors [79]. Otten, Mann, van Berkum, and Jonas [32], using electroencephalography (EEG), have evaluated how the brain reacts to humiliation and investigated what happens when this humiliation is accompanied by public laughter. They have provided evidence that the brain reacts differently after reading humiliating scenarios than complimentary scenarios [80]. However, Gendron and Barrett [81] have argued that emotions cannot be justified by brain regions. 


\subsection{The Current Study}

Previous studies have focused solely on social exclusion $[33,40,74,76,82]$ or verbal harassment. The main objective of the present study was to investigate the effects of cyberbullying on emotional, stress and coping responses. We also examined how cyberbullying via social interaction and publicity affect emotional and stress responses. We hypothesized that cyberbullying would elevate negative emotional reactions to a greater extent than socially positive interactions. Cyberbullying in public rather than in private was predicted to induce greater negative emotional reactions, as reflected by lower PA and higher NA. Cyberbullying in public was anticipated to generate higher negative stress responses than socially positive interactions, as indicated by at least one of the following attributes: A reduction in task engagement, an increase in distress, and/or an increase in worry. We also predicted that cyberbullying in public rather than in private would induce different levels of coping strategies, reflected by task-focused coping, emotion-focused coping, and/or increased avoidance, as indicated by at least one of the following attributes: Decreased task focus, increased emotion focus, and/or increased avoidance.

\section{Materials and Methods}

Various experimental approaches have been used to study cyberbullying in laboratory environments. Cyberball has been used to study social ostracism [35]. Role playing has also been used to assess how participants react in different fictional settings [83], and chatrooms have been investigated $[76,82,84-86]$. Wolf et al. [87] have used an online ostracism paradigm and compared it with the Cyberball game. They have reported that both tools are effective in providing a valid measure of social exclusion. The current study focused on the effects of cyberbullying on emotional, stress, and coping responses. We also examined how cyberbullying via social interaction and publicity affect emotional and stress responses.

\subsection{Participants}

Twenty-nine undergraduate students (16 females aged $18.25 \pm 0.58$ years and 13 males aged $18.46 \pm 1.13$ years) volunteered to participate in the experiment. The Institutional Review Board approved the current method. As compensation for their efforts, the participants were given the option to receive either class credit or a monetary compensation of $\$ 30$. They were self-declared to be right-handed and healthy and to have no known neurological or psychological disorders. The participants were debriefed concerning the purpose of the experiment before leaving the research facility.

\subsection{Subjective Measures}

Many psychometric tools have been developed to measure emotions. One of the highly cited and validated tools is the Positive and Negative Affect Schedule (PANAS). PANAS was built around the PANA model (Watson et al., 1988). The PANAS scale assesses affective state in two dimensions: PA and NA [48]. PANAS has ten items dedicated to measuring PA (e.g., alert, attentive, active, determined, and inspired) and ten items to measure NA (e.g., upset, hostile, afraid, nervous, and ashamed) [48]. During the experiment, participants rated their feelings before starting the experiment and during each trial via a Likert scale. The instrument has strong internal consistency, with Cronbach's alpha $\geq 0.84$ [88].

The Dundee Stress State Questionnaire (DSSQ) is a widely used tool to assess the level of stress during a task. DSSQ was developed by Matthews et al. [89] to measure the level of stress during assigned tasks. Matthews, Szalma, Panganiban, Neubauer, and Warm [61] have linked stress factors to Lazarus' Transactional Model. Hobfoll [62] has indicated that stress is a result of how situations are appraised. DSSQ evaluates three types of stressors: Distress, task engagement, and worry. The Dundee Stress State Questionnaire (DSSQ-3) measures stress through a 30-item questionnaire [90] and is a highly validated short version of the original DSSQ with an alpha value ranging from 0.78 to 0.83 [61]. 
The selection of the short version over the original was motivated by the overall experimental duration. The Coping Inventory for Stressful Situations (CITS) [91] is a 21-item questionnaire with an alpha coefficient ranging from 0.84 to 0.86 , measuring how people cope with stressful events. was used to complement the DSSQ-3 that measures three coping forms (task-focused coping, emotion-focused coping, and avoidance).

\subsection{Data Analysis}

We used a baseline condition to scale any changes for individuals. All subsequent analyses were performed using Nonparametric Friedman's test was conducted to test the effect of the experimental condition on change scores (condition-baseline) to test the effect of the experimental condition.

There were eight dependent variables (emotional responses: PA and NA; stress responses: Engagement, distress, and worry; and coping strategy: Task-focused, emotion-focused, and avoidance). Each was subjectively collected before the beginning of the experiment and then after each of the exposures. Spearmans correlation analyses were used to assess the degree of association among the responses, as reported by the PANAS, DSSQ and CITS instruments. The study's significance level was set at $p<0.05$, and all statistical procedures were conducted in SPSS version 24.0 (SPSS Inc., Chicago, IL, USA).

\subsection{Study 1: Cyberbullying through Social Exclusion}

\subsubsection{Research Variables}

The independent variables in this study were (1) cyberbullying publicity and (2) social interaction. Each of these independent variables had two levels (i.e., cyberbullying publicity: Private vs. public; and social interaction: Exclusion "negative," vs. inclusion "positive"). The dependent variables were emotional response (PA and NA), stress response (task engagement, distress, and worry), and coping response (task-focused, emotion-focused, and avoidance).

\subsubsection{Experimental Stimuli}

The Cyberball game [35] has been widely used in behavioral and neuroimaging studies to induce social exclusion $[33,35,76]$. The validity of this game has been demonstrated to induce a feeling of social exclusion, although the participants know that they are playing with software [92]. The game has been cited more than 200 times in social exclusion studies [40]. This paradigm is a suitable methodology to study the reactions of people to being excluded.

The game begins with a cover story leading participants to believe that they are playing with another player on the campus. The participants actually play with a pre-programmed player. This cover story is vital to success and helps "avoid demand characteristics" (i.e., when participants unintentionally change their behavior to fit the test's purpose) [93]. The game was originally conducted to study social interactions using three or more players. Thus, this game was originally designed to study social exclusion with only publicity. However, in the current study, to emulate the private condition in this experiment, we partially modified the original Cyberball game. The three-player game was modified by converting the third player into a wall (Figure 1). The purpose of the wall was to allow the ball to bounce back to the pre-programmed player.

During the exclusion condition, the pre-programmed player passed the ball to the participant once and then kept bouncing the ball to the wall without passing it to the participant until the end of the block. During the inclusion condition, the ball was passed among players equally. During public conditions, the ball was passed among four players including the participant. During the inclusion state, the participant received the ball equally on a regular basis. However, during the exclusion condition, the participant received the ball only three times during the first ten throws and subsequently was excluded until the trial ended. 


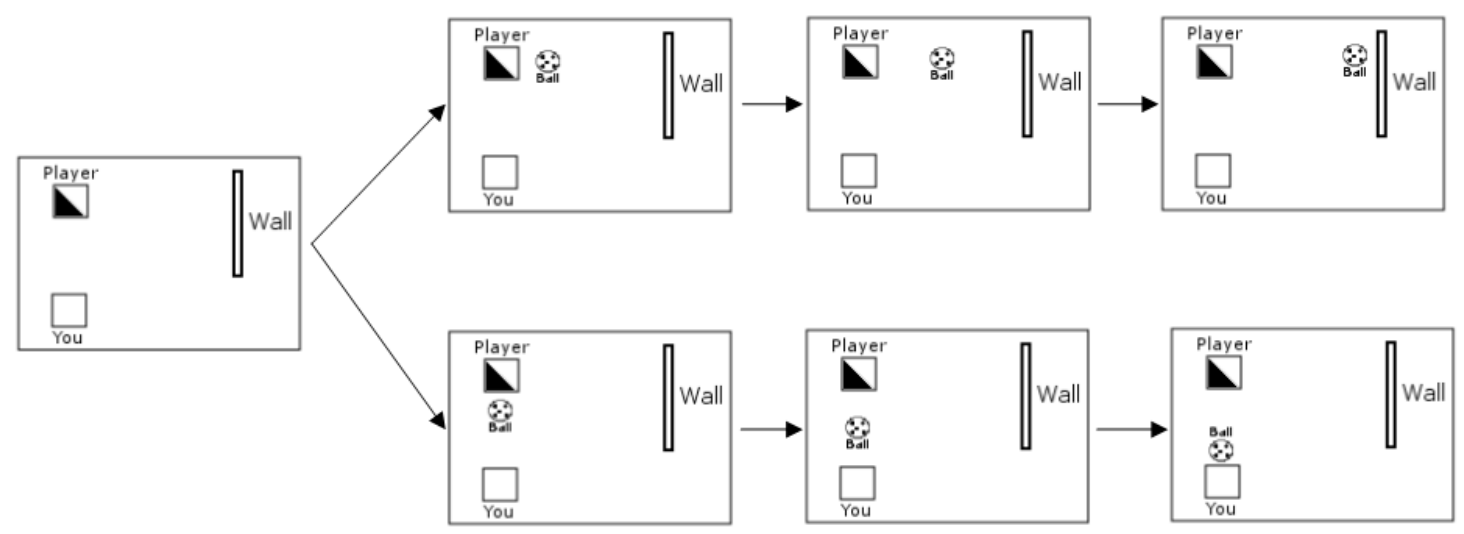

Figure 1. The modified Cyberball schematic diagram used during the private session. The ball is passed between the participant and the computerized participant (private-inclusion), or the computerized participant bounces the ball back to the wall (private-exclusion).

\subsubsection{Experimental Procedure}

The participants were told that they would be participating in a study entitled "Assessing online game and reading online comments". This title was decided upon to distract the participants from the actual purpose of the experiment. The participants were also screened for having been caffeine-free for at least $3 \mathrm{~h}$ and alcohol-free at least $24 \mathrm{~h}$ before participating. Each participant read the consent form and provided demographic data including body weight, height, handedness, and age. The room was equipped with a PC running presentation software.

There were five experimental blocks. The first block was the baseline, in which the participants played Cyberball in a neutral condition, which, in this context, was no exclusion. After that, the participant was presented with the remaining four experimental blocks in random order (social exclusion in public, social inclusion in public, social exclusion in private, and social inclusion in private). Each experimental block comprised 50 throws. At the end of each block, the participant was requested to fill in a post-experiment questionnaire involving the PANAS, DSSQ-3, and CITS scales. The sequence of the experiment is illustrated in Figure 2.

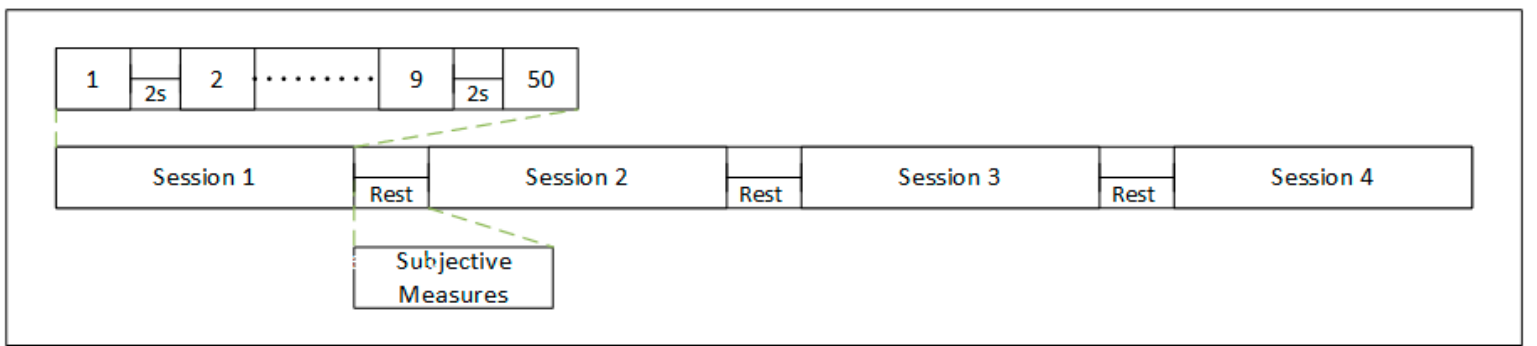

Figure 2. Social exclusion study experimental tasks. Each session included 50 throws, and every throw took $1.5 \mathrm{~s}$ separated by 1 to $2 \mathrm{~s}$ between throws. After the end of each session, the participants self-assessed their feelings using the Positive and Negative Affect Schedule (PANAS), Dundee Stress State Questionnaire (DSSQ), and Coping Inventory for Stressful Situations (CITS) questionnaires.

\subsubsection{Results}

Descriptive results are given in Table 1. The nonparametric Friedman's test of differences among repeated measures of PA showed that these differences were significant ant $(\mathrm{Fr}=9.143, p<0.01)$. Social exclusion induced significantly lower PA than inclusion. The Friedman's test of differences among repeated measures of NA showed that these differences were significant for NA ( $\mathrm{Fr}=9.000$, $p<0.001)$. Inclusion induced a significantly lower NA than exclusion. This result shows that negative social interactions induce negative emotional responses. 
The Friedman's test of differences among repeated measures of Engagement showed that these differences were significant $(\mathrm{Fr}=4.481, p<0.05)$. Social exclusion reduced engagement, in contrast to social inclusion. The Friedman's test of differences among repeated measures of Distress showed that these differences were significant $(\mathrm{Fr}=9.966, p<0.01$ ). Here, social exclusion evoked greater scores than social inclusion. The Friedman's test of differences among repeated measures of Worry showed that these differences are not significant $(\mathrm{Fr}=0.000, p>0.05)$.

The non-parametric Friedman test of differences among repeated measures of avoidance showed that these differences are not significant $(\mathrm{Fr}=3.522, p=0.061)$. Social exclusion conditions evoked higher scores than social inclusion conditions. The Friedman's test of differences among repeated measures of Emotion-Focus showed that these differences were significant $(\mathrm{Fr}=5.538, p<0.05)$. Social exclusion evoked higher emotion-focused scores than social inclusion. No significant main effects or interaction effects were found for task-focused scores as a dependent variable. No interactive effects were found for any dependent variables. A summary of significant results is given in Table 2. The histograms in Figures $3-5$ graphically illustrate the emotional, stress, and coping factors. To further explore these results, we performed a Spearman correlation analysis (Table 3) to assess the relationships among subjective variables. Distress was moderately and negatively correlated with PA and moderately and positively correlated with NA.

Table 1. Social exclusion study: Subjective variables (means $\pm \mathrm{SD}$ ) measured as magnitudes of changes from baseline.

\begin{tabular}{ccc}
\hline & Exclusion & Inclusion \\
\hline Positive affect & $-10.54 \pm 6.36$ & $-7.35 \pm 6.8$ \\
Negative affect & $1.45 \pm 2.27$ & $0.00 \pm 2.04$ \\
Engagement & $-5.5 \pm 5.32$ & $-3.78 \pm 5.16$ \\
Distress & $2.66 \pm 4.8$ & $0.76 \pm 5.04$ \\
Worry & $-1.76 \pm 6.94$ & $-2.26 \pm 6.83$ \\
Task focus & $-3.09 \pm 3.73$ & $-2.56 \pm 3.18$ \\
Emotion focus & $-4.35 \pm 6.72$ & $-5.44 \pm 5.78$ \\
Avoidance & $0.11 \pm 4.21$ & $-1.02 \pm 3.67$ \\
\hline
\end{tabular}

Table 2. Social exclusion study: Summary of significant subjective factors with their effect sizes.

\begin{tabular}{cc}
\hline Factor & Friedman's Test \\
\hline Positive Affect & $(\mathrm{Fr}=9.143, p<0.01)$ \\
\hline Negative affect & $(\mathrm{Fr}=9.000, p<0.01)$ \\
\hline Engagement & $(\mathrm{Fr}=4.481, p<0.034)$ \\
\hline Distress & $(\mathrm{Fr}=9.966, p<0.01)$ \\
\hline Worry & $(\mathrm{Fr}=0.000, p=1)$ \\
\hline Task focus & $(\mathrm{Fr}=0.143, p=0.705)$ \\
\hline Emotion focus & $(\mathrm{Fr}=5.538, p<0.05)$ \\
\hline Avoidance & $(\mathrm{Fr}=3.522, p=0.061)$ \\
\hline
\end{tabular}

Table 3. Social exclusion study: Spearman's correlation coefficients among subjective data.

\begin{tabular}{|c|c|c|c|c|c|c|c|}
\hline & (1) & (2) & (3) & (4) & (5) & (6) & (7) \\
\hline Positive affect & 1 & & & & & & \\
\hline Negative affect & $-0.375^{* *}$ & 1 & & & & & \\
\hline Engagement & $0.596^{* *}$ & $-0.271^{* *}$ & 1 & & & & \\
\hline Distress & $-0.409 * *$ & $0.512 * *$ & $-0.521^{* *}$ & 1 & & & \\
\hline Worry & -0.015 & 0.199 * & $-0.247^{* *}$ & 0.323 ** & 1 & & \\
\hline Task focus & $0.393 * *$ & 0 & $0.455^{* *}$ & -0.208 * & 0.124 & 1 & \\
\hline Emotion focus & -0.096 & $0.282 * *$ & -0.134 & $0.343^{* *}$ & $0.251 * *$ & $0.235^{*}$ & 1 \\
\hline Avoidance & $-0.351^{* *}$ & $0.370^{* *}$ & $-0.470 * *$ & $0.325^{* *}$ & 0.161 & -0.089 & $0.323 * *$ \\
\hline Mean & -8.94 & 0.72 & -4.64 & 1.71 & -2.01 & -2.82 & -4.89 \\
\hline SD & 7.232 & 2.535 & 5.876 & 5.375 & 7.243 & 4.066 & 6.48 \\
\hline
\end{tabular}




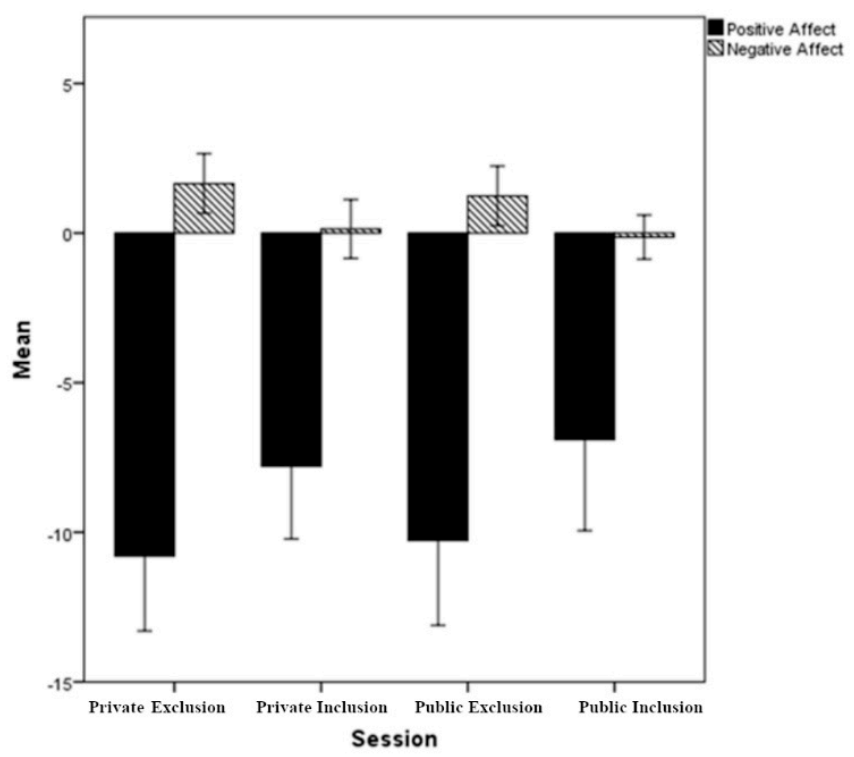

Figure 3. Social exclusion study: Subjective responses, calculated as the magnitude of changes from baseline scores (condition score-baseline score). Error bars indicate the $95 \%$ confidence interval standard error. Emotional responses were measured as factors of positive affect and negative affect using PANAS. PA indicates positive affect; NA indicates negative affect. Social exclusion showed a significant increase in NA and a significant reduction in PA, in contrast to social inclusion.

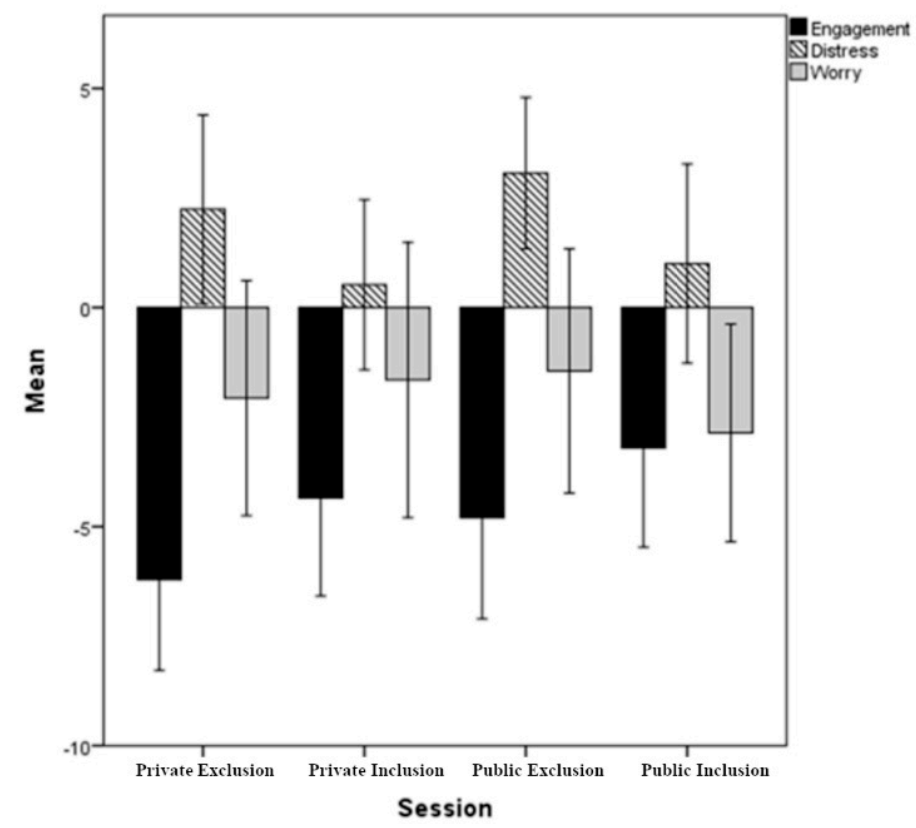

Figure 4. Social exclusion study: Subjective responses, calculated as the magnitude of changes from baseline scores (condition score-baseline score). Error bars indicate the $95 \%$ confidence interval standard error. Stress responses, comprising factors of engagement, distress, and worry. Stress response was measured by DSSQ-3. Social exclusion was reported as a significant increase in distress and a reduction in engagement, in contrast to social inclusion. 


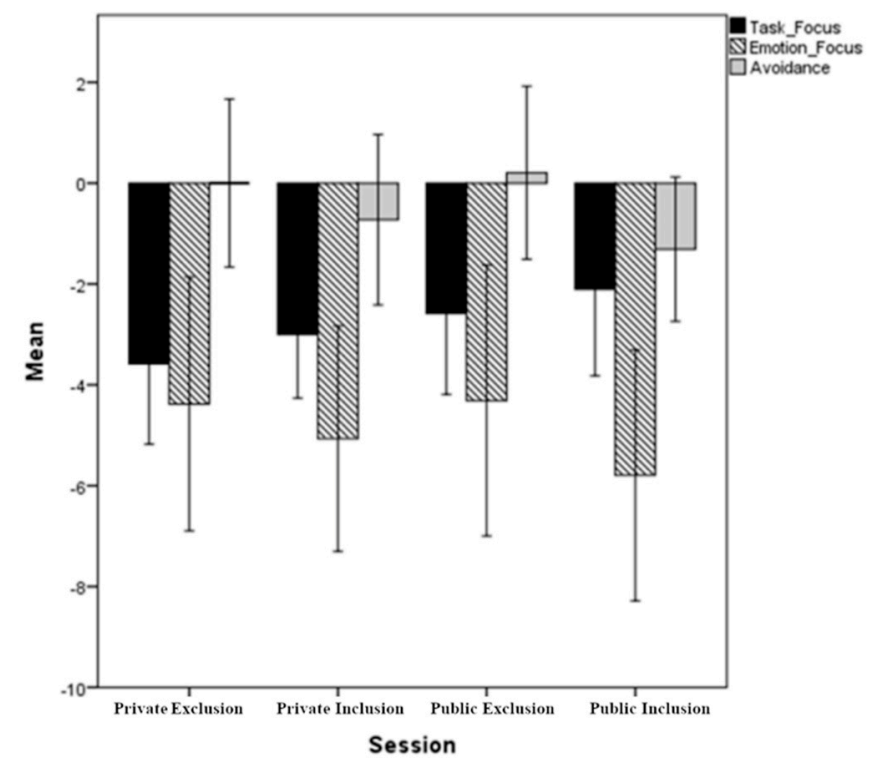

Figure 5. Social exclusion study: Subjective responses, calculated as the magnitude of changes from baseline scores (condition score-baseline score). Error bars indicate the $95 \%$ confidence interval standard error. Coping responses were reported as task-focused coping, emotion-focused coping, and avoidance. Coping was measured with CITS. Social exclusion, compared with social inclusion, resulted in a significant increase in the emotion-focused coping and the avoidance dimensions. No significant main were observed for the task-focused coping dimension.

\subsection{Study 2: Cyberbullying through Verbal Harassment}

\subsubsection{Research Variables}

The independent variables in this study were (1) cyberbullying publicity and (2) social interaction. Each of these independent variables had two levels (i.e., cyberbullying publicity: Private vs. public; and social interaction: Impolite comments "negative," vs. complimentary comments "positive"). The dependent variables were emotional response (PA and NA), stress response (task engagement, distress, and worry), and coping response (task-focused coping, emotion-focused coping, and avoidance).

\subsubsection{Experimental Stimuli}

This experiment was managed via a hypothetical vignette scenario and a Variable Serial Visual Presentation (VSVP) procedure $[93,94]$. The scenario requested participants to use their mental skills to mentally visualize the experience while reading a sequence of online comments. Those comments were presented either via Twitter (public) or personal email (private). Impolite/complimentary comments were presented in a "confrontational situation" similar to that in Wellsby et al. [95]. The VSVP experimental methodology relied on presenting sentences in a sequence of words with a time-stamped methodology.

The typical paradigm used to display sentences in EEG studies is serial visual presentation (SVP). SVP displays a sentence in a word-by-word sequence at a fixed rate. This word-by-word presentation ensures that the onset marker is associated with the critical word. SVP remains a valid presentation tool, but it does not present words in a natural reading manner [94]. Therefore, [32,94] established a procedure to overcome this problem. This procedure, VSVP, presents words according to variable length, on the basis of their positions within the sentence. With the procedure, words are measured according to the following rules: 
1. The non-critical word should be computed as $187 \mathrm{~ms}+$ number of letters $* 27 \mathrm{~ms}$.

2. The maximum word length is 10 .

3. The critical word and the subsequent word should be displayed at a fixed rate of $346 \mathrm{~ms}$.

4. Between each word, the screen should be blank for $106 \mathrm{~ms}$.

5. The final word should be extended to at least $293 \mathrm{~ms}$.

6. At least a 1000-ms pause should be specified until the next sentence begins.

7. All sentences should be roughly equal in length.

Between each trial, $2 \mathrm{~s}$ was added to allow the participants to blink. In this experiment, impolite statements were adapted from a list compiled by Giumetti, Hatfield, Scisco, Schroeder, Muth, and Kowalski [56], Otten, Mann, van Berkum, and Jonas [32], and Siakaluk et al. [96]. For example: "You are one of the most lovable people that I met" was used for the compliment session, and "I find you despicable and disgusting" was used for the verbal harassment session. The baseline session involved reading neutral words adapted from [96]. An example of neutral sentence is "I think I have a doctor's appointment." The sentences were checked pragmatically according to the psychometric software Linguistic Inquiry and Word Count $[97,98]$. The critical word was specified as the first impolite word e.g., "disgust" or a complimentary word e.g., "fabulous" [32] (Figure 6). The complimentary words were adapted from Otten, Mann, van Berkum, and Jonas [32]. Each participant participated in all four blocks (verbal harassment in private, a complimentary word in private, verbal harassment in public, and a complimentary word in public). Sentences were separated by a 2-s fixation marker appearing at the center of the screen (Figure 7).

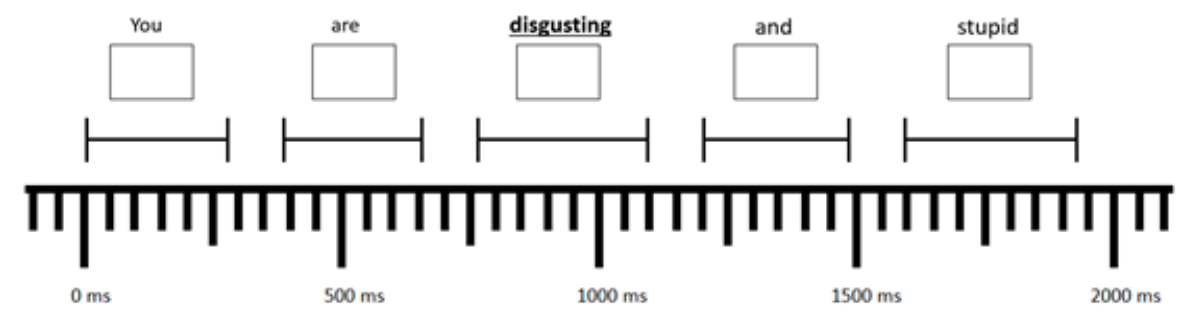

Figure 6. Verbal harassment study: Illustration of the sequence sentences presentation. The critical word, as used in Otten, Mann, van Berkum, and Jonas [32], is in bold.

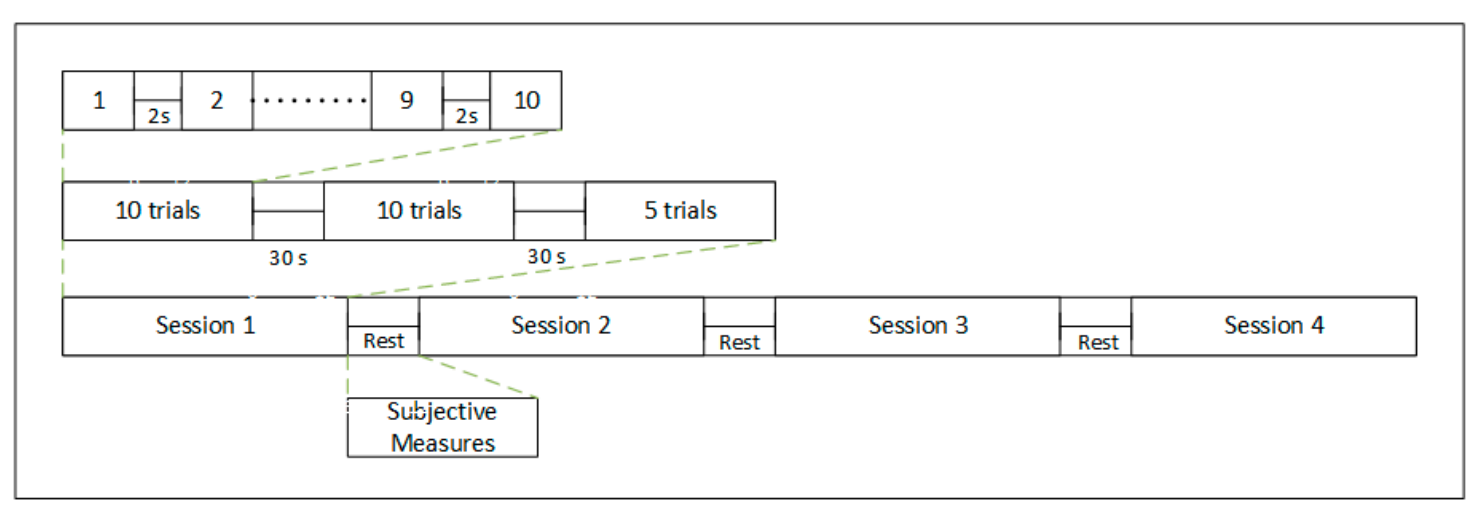

Figure 7. Verbal harassment experimental sequence. Each session includes 25 sentences. At the end of every sentence, a fixation screen was set to last between 1 and $2 \mathrm{~s}$. After the end of every ten trials, a 30-s break was given. At the end of each session, the participant's feelings were assessed with the PANAS, DSSQ, and CITS questionnaires. 


\subsubsection{Experimental Procedure}

Each participant read the consent form and provided demographic data including body weight, height, handedness, and age. Before each experiment, the participants were familiarized with the upcoming task in a practice session and were then randomly assigned to start with one of the two experiments. Each participant performed all interventions randomly to reduce any possible confounding due to a sequence effect. Each intervention encompassed different hypothetical scenarios according to the experimental design.

The participants were seated $60 \mathrm{~cm}$ from a screen in an electrically shielded room. The fixation condition in this experiment was represented by a blank screen with a cross at the middle of the page. This experimental paradigm included verbal harassment with a procedure using the VSVP developed by Van Berkum and colleagues [32,94]. Each participant was requested to complete the PANAS, DSSQ-3, and CITS post-experiment questionnaires after each session. The experiment concluded with a debriefing to clarify the actual purpose of the experiment and why it was important to have a cover story. Finally, as a proactive measure, the experiment's debriefer recommended that participants visit UCF's counseling service if they believed that they had been affected by the experiment.

\subsubsection{Results}

Descriptive results are given in Table 4. A Friedman's test among repeated measures of PA was conducted and indicated that these differences were significant $(\mathrm{Fr}=6.259, p<0.05)$. A Friedman's test among repeated measures of NA was conducted and indicated that these differences were significant $(\mathrm{Fr}=16.333 p<0.01)$. Complimentary comments induced a significantly lower NA than impolite comments.

A Friedman's test among repeated measures of Engagement was conducted and indicated that these differences are not significant $(\mathrm{Fr}=3.000 p=0.083)$. In terms of stress responses, the results for engagement showed impolite comments decreased engagement, in contrast to complimentary comments. A Friedman's test among repeated measures of Distress was conducted and indicated that these differences were significant $(\mathrm{Fr}=12.448, p<0.01)$. Impolite comments increased distress, in contrast to complimentary conditions. A Friedman's test among repeated measures of Worry was conducted and indicated that these differences are not significant $(\mathrm{Fr}=0.571, p=0.450)$. Here, impolite comments evoked greater scores for worry than complimentary comments.

In terms of coping responses, a Friedman's test among repeated measures of Task-Focus was conducted and indicated that these differences are not significant $(\mathrm{Fr}=3.240, p=0.072)$. Impolite comments reduced task-focused coping, in contrast to complimentary comments. A Friedman's test among repeated measures of emotion-focused comping was conducted and indicated that these differences were significant $(\mathrm{Fr}=13.500 p<0.01)$. Here, impolite comments evoked greater emotion-focused coping than complimentary comments. A Friedman's test among repeated measures of avoidance coping was conducted and indicated that these differences were significant $(\mathrm{Fr}=8.167$, $p<0.01)$. Impolite comments, compared with complimentary comments, increased avoidance. No interactive effects were found for any dependent variables, and a summary of significant results is given in Table 5. The histograms in Figures 8-10 graphically illustrate the emotional, stress, and coping factors.

To further explore the results, we performed a Spearman's correlation analysis (Table 6) to assess the relationships among independent variables. Distress showed a strongly negative correlation with PA and a strongly positive correlation with negative affect. The mean score differences from baseline changes are reported in Figures 8-10. 


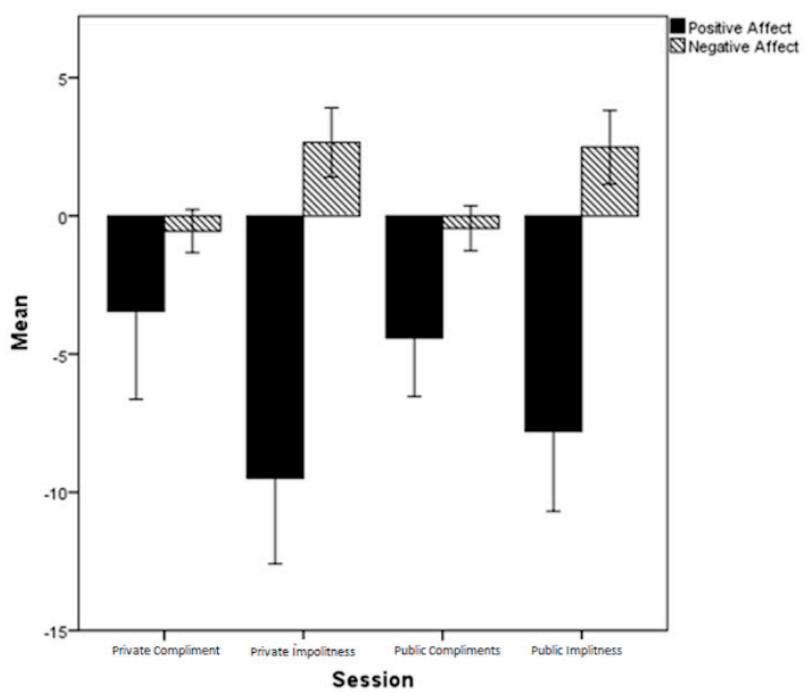

Figure 8. Verbal harassment study: subjective responses were calculated as the magnitude of changes from baseline scores (condition score-baseline score). Error bars indicate the $95 \%$ confidence interval standard error. Emotional responses were measured as factors of positive affect and negative affect with PANAS. PA indicates positive affect; NA indicates negative affect. Impolite comments induced a significant increase in NA and a reduction in PA, in contrast to complimentary comments

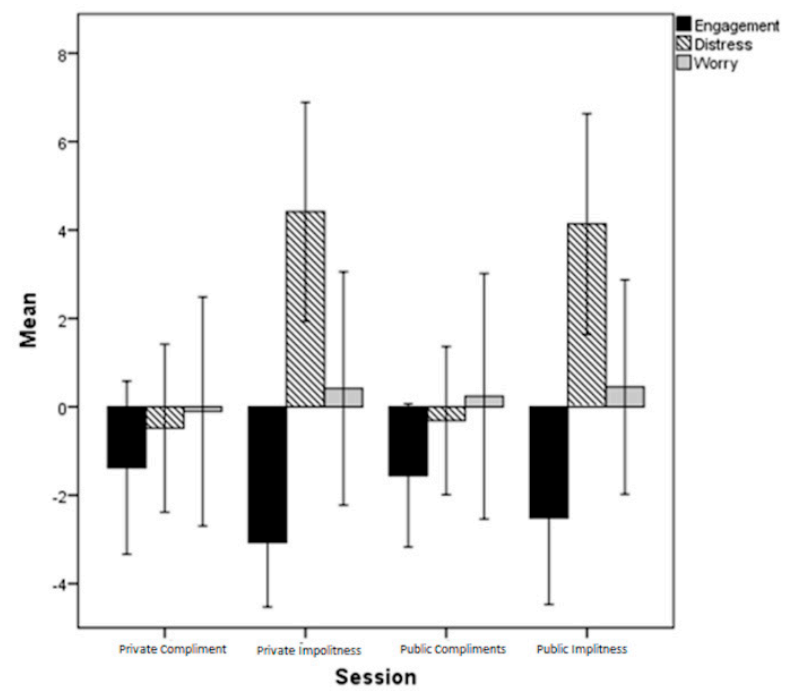

Figure 9. Verbal harassment study: subjective responses were calculated as the magnitude of changes from baseline scores (condition score-baseline score). Error bars indicate the $95 \%$ confidence interval standard error. Stress responses comprised factors of engagement, distress and worry. Stress response was measured by DSSQ-3. Coping response comprised task-focused coping, emotion-focused coping, and avoidance. Coping was measured with CITS. Impolite comments, compared with complimentary comments, resulted in significantly reduced task-focused coping, increased emotion-focused coping, and increased avoidance. 


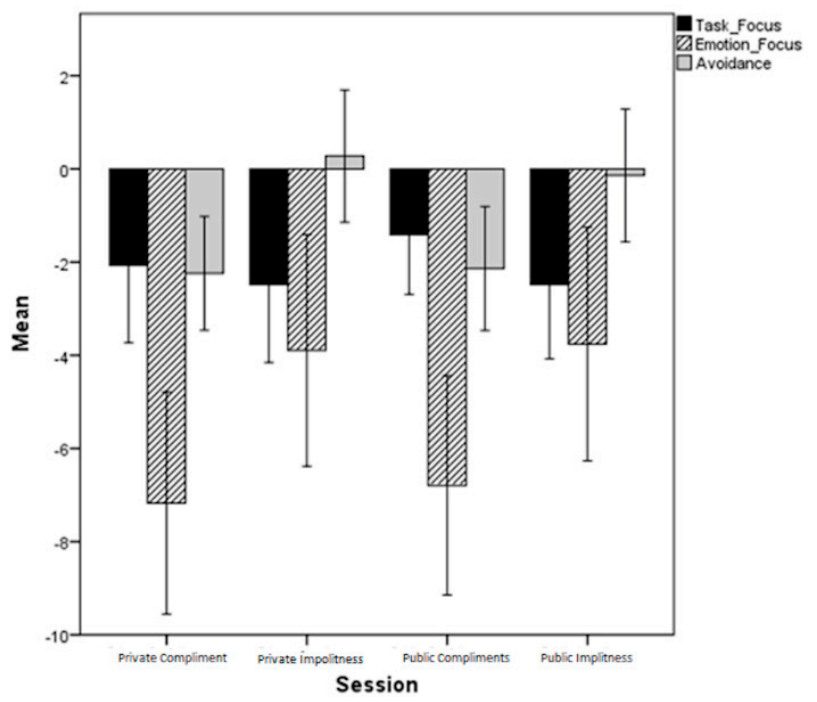

Figure 10. Verbal harassment study: subjective responses were calculated as the magnitude of changes from baseline scores (condition score-baseline score). Error bars indicate the $95 \%$ confidence interval standard error. Coping response comprised task-focused coping, emotion-focused coping, and avoidance. Coping was measured with CITS. Impolite comments, compared with complimentary comments, resulted in significantly reduced task-focused coping, increased emotion-focused coping, and increased avoidance.

Table 4. Verbal harassment study: Subjective variables (means \pm SD) measured as a magnitude of changes from the baseline.

\begin{tabular}{ccc}
\hline & Impoliteness & Complimentary \\
\hline Positive affect & $-8.64 \pm 7.38$ & $-3.94 \pm 6.51$ \\
Negative affect & $2.57 \pm 3.25$ & $-0.5 \pm 1.9$ \\
Engagement & $-2.8 \pm 4.17$ & $-1.47 \pm 4.32$ \\
Distress & $4.28 \pm 6.23$ & $-0.4 \pm 4.47$ \\
Worry & $0.44 \pm 6.47$ & $0.07 \pm 6.74$ \\
Task focus & $-2.49 \pm 4.14$ & $-1.75 \pm 3.67$ \\
Emotion focus & $-3.83 \pm 6.28$ & $-6.99 \pm 6$ \\
Avoidance & $0.07 \pm 3.52$ & $-2.19 \pm 3.07$ \\
\hline
\end{tabular}

Table 5. Verbal harassment study: Summary of significant subjective factors and effect sizes.

\begin{tabular}{cc}
\hline Factor & Friedman's Test \\
\hline Positive Affect & $(\mathrm{Fr}=6.259, p<0.05)$ \\
\hline Negative affect & $(\mathrm{Fr}=16.333, p<0.01)$ \\
\hline Engagement & $(\mathrm{Fr}=3.000, p<0.083)$ \\
\hline Distress & $(\mathrm{Fr}=12.448, p<0.01)$ \\
\hline Worry & $(\mathrm{Fr}=0.571, p=0.450)$ \\
\hline Task focus & $(\mathrm{Fr}=3.240, p=0.072)$ \\
\hline Emotion focus & $(\mathrm{Fr}=13.500, p<0.01)$ \\
\hline Avoidance & $(\mathrm{Fr}=8.167, p<0.01)$ \\
\hline
\end{tabular}


Table 6. Verbal harassment study: Nonparametric Spearman's correlation coefficient coefficients among subjective emotional, stress, and coping responses.

\begin{tabular}{|c|c|c|c|c|c|c|c|}
\hline & (1) & (2) & (3) & (4) & (5) & (6) & (7) \\
\hline Positive affect & 1 & & & & & & \\
\hline Negative affect & $-0.479 * *$ & 1 & & & & & \\
\hline Engagement & $0.701^{* *}$ & $-0.354 * *$ & 1 & & & & \\
\hline Distress & $-0.729 * *$ & $0.647^{* *}$ & $-0.620^{* *}$ & 1 & & & \\
\hline Worry & $-0.205 *$ & 0.115 & $-0.345^{* *}$ & $0.328^{* *}$ & 1 & & \\
\hline Task focus & $0.395^{* *}$ & 0.008 & $0.449 * *$ & $-0.324^{* *}$ & $-0.273^{* *}$ & 1 & \\
\hline Emotion focus & $-0.188 *$ & $0.212 *$ & -0.093 & 0.128 & -0.167 & 0.093 & 1 \\
\hline Avoidance & $-0.266^{* *}$ & $0.471^{* *}$ & $-0.338^{* *}$ & $0.403^{* *}$ & 0.042 & 0.009 & $0.462^{* *}$ \\
\hline Mean & -6.28 & 1.03 & -2.13 & 1.94 & 0.25 & -2.11 & -5.41 \\
\hline SD & 7.815 & 3.187 & 4.62 & 6.094 & 6.78 & 4.071 & 6.513 \\
\hline
\end{tabular}

\subsection{Verbal Harassment through Impolite Comments vs. Social Exclusion}

The two studies in this research used the same participants, thus enabling a comparison of subjective variables across the two studies. In this section, the two negative social interactions (verbal harassment via impolite comments and social exclusion) were statistically compared. Eight dependent variables of interest (emotional responses: Positive affect and negative affect; stress responses: Engagement, distress and worry; and coping responses: Task-focused coping, emotion-focused coping and avoidance) were subjectively collected before the beginning of the experiment and then after each of the sessions. Descriptive results are given in Table 7.

Table 7. Verbal harassment via impolite comment vs. social exclusion: Subjective variables (means \pm SD) measured as a magnitude of changes from baseline.

\begin{tabular}{ccc}
\hline & Social Exclusion & Impoliteness \\
\hline Positive affect & $-10.54 \pm 6.36$ & $-8.64 \pm 7.38$ \\
Negative affect & $1.45 \pm 2.27$ & $2.57 \pm 3.25$ \\
Engagement & $-5.5 \pm 5.32$ & $-2.8 \pm 4.17$ \\
Distress & $2.66 \pm 4.8$ & $4.28 \pm 6.23$ \\
Worry & $-1.76 \pm 6.94$ & $0.44 \pm 6.47$ \\
Task focus & $-3.09 \pm 3.73$ & $-2.49 \pm 4.14$ \\
Emotion focus & $-4.35 \pm 6.72$ & $-3.83 \pm 6.28$ \\
Avoidance & $0.11 \pm 4.21$ & $0.07 \pm 3.52$ \\
\hline
\end{tabular}

In terms of emotional responses, a Friedman's test among repeated measures of NA was conducted and indicated that these differences are not significant $(\mathrm{Fr}=3.240, p=0.257)$. No significant differences in PA between impolite comments and social exclusion were found. In terms of stress responses, a Friedman's test among repeated measures of Engagement was conducted and indicated that these differences were significant $(\mathrm{Fr}=8.333 p<0.01)$. Here, social exclusion, compared with impolite comments, decreased in engagement score. A Friedman's test among repeated measures of Distress was conducted and indicated that these differences are not significant $(\mathrm{Fr}=1.000, p=0.317)$. A Friedman's test among repeated measures of Worry was conducted and indicated that these differences were significant $(\mathrm{Fr}=7.000 p<0.01)$. Impolite comments induced higher worry than social exclusion. In terms of coping responses, no significant difference was observed between impolite comments and social exclusion. A summary of the significant results is illustrated in Table 8 . The mean score differences from baseline changes are reported in Figures 11-13. 


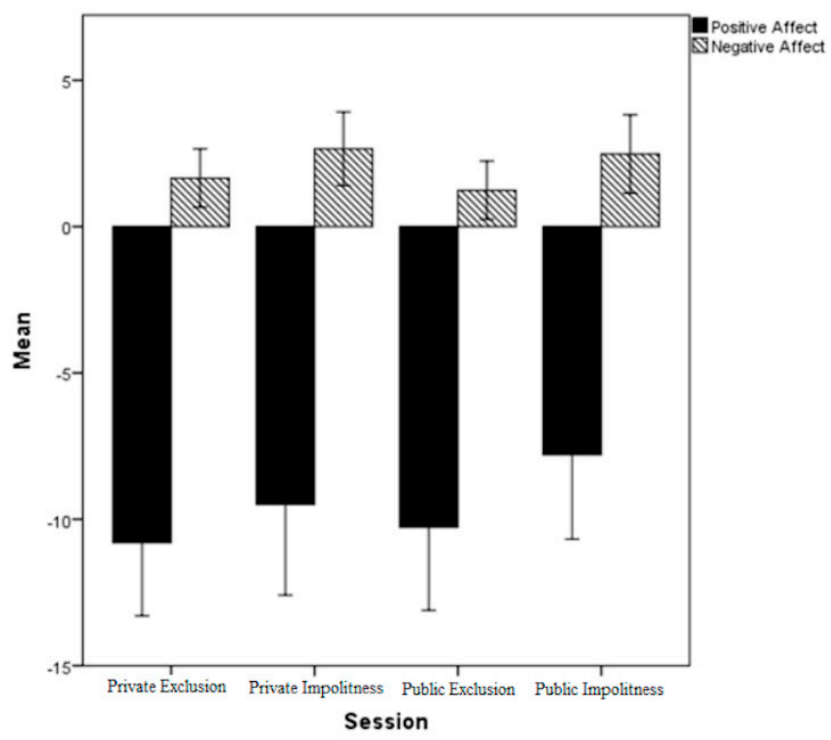

Figure 11. Subjective responses between negative social interactions (social exclusion vs. verbal harassment via impolite comments) in both experiments. Error bars indicate $95 \%$ confidence interval standard error. Emotional response was measured as positive affect and negative affect with PANAS. PA indicates positive affect; NA indicates negative affect. Verbal harassment via impolite comments showed a significant increase in NA.

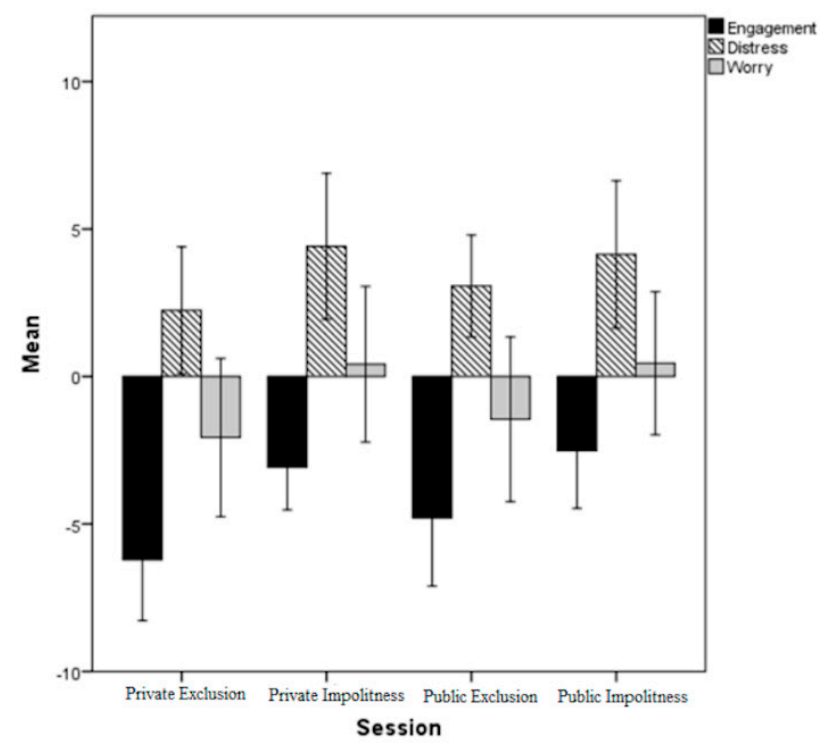

Figure 12. Subjective responses between negative social interactions (social exclusion vs. verbal harassment via impolite comments) in both experiments. Error bars indicate $95 \%$ confidence interval standard error. Stress responses comprised engagement, distress, and worry. Stress response was measured by DSSQ-3. Impolite comments induced a near-significant increase in the distress dimension, a significant increase in the worry dimension, and a significant increase in engagement, as compared with complimentary comments. 


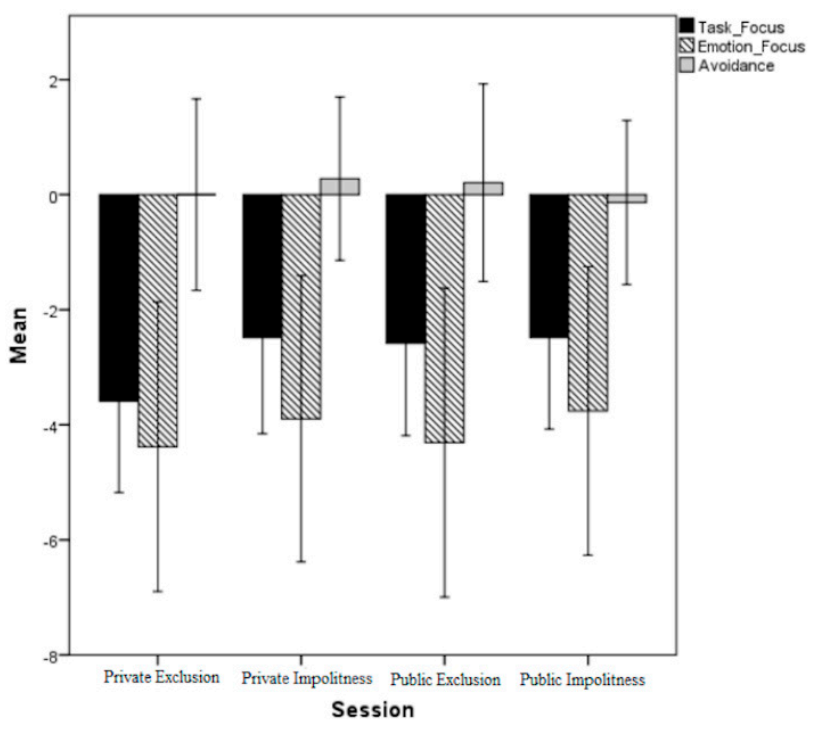

Figure 13. Subjective responses between negative social interactions (social exclusion vs. verbal harassment via impolite comments) in both experiments. Error bars indicate $95 \%$ confidence interval standard error. Coping responses comprised task-focused coping, emotion-focused coping, and avoidance. Coping was measured with CITS. No significant main effect difference was observed between impolite comments and social exclusion for all coping responses.

Table 8. Verbal harassment via impolite comments vs. social exclusion: Summary of significant subjective factors.

\begin{tabular}{cc}
\hline Factor & Friedman's Test \\
\hline Positive Affect & $(\mathrm{Fr}=1.286, p<0.257)$ \\
\hline Negative Affect & $(\mathrm{Fr}=3.240, p<0.072)$ \\
\hline Engagement & $(\mathrm{Fr}=8.333, p<0.004)$ \\
\hline Distress & $(\mathrm{Fr}=1.000, p=0.317)$ \\
\hline Worry & $(\mathrm{Fr}=7.000, p<0.001)$ \\
\hline Task focus & $(\mathrm{Fr}=3.571, p=0.059)$ \\
\hline Emotion focus & $(\mathrm{Fr}=0.143, p=0.705)$ \\
\hline Avoidance & $(\mathrm{Fr}=1.000, p=0.317)$ \\
\hline
\end{tabular}

\section{Discussion and Conclusions}

The results of these two experiments contribute to research investigating the psychosocial effects of cyberbullying. Our findings specifically demonstrated the effects of cyberbullying through social exclusion and verbal harassment on emotional, stress, and coping responses. These effects were studied in terms of social interaction and cyberbullying publicity. Social interaction influenced subjective emotional, and stress responses. In general, cyberbullying studies remain in their infancy [99,100], but the preliminary findings of this research make a substantial contribution to the literature by answering the question of which type of cyberbullying has more significant effects in terms of emotional, stress, and coping responses. It also sheds light on the involvement of publicity as a factor.

Emotional responses. Cyberbullying through social exclusion and verbal harassment was predicted to induce negative emotional reactions, as a function of two independent dimensions (PA and NA). This hypothesis was supported by both studies. Thus, if a person is being cyberbullied, a lower level of PA and greater NA would be expected. Our results also suggest that being a victim of cyberbullying might destroy the victim's positive wellbeing. In line with previous studies conducted by Ruggieri, Bendixen, Gabriel, and Alsaker [74], our results indicate that negative online interactions 
have negative emotional impacts. Cyberbullying victims might suffer general stress during the day to day activities. They are likely to have school stress and health problems like headaches or nausea [101]. Worth noting that during social interaction in a computing environment, emotions are not easily perceived. Thus, cyberbullies might not observe the emotional impact on their victims [28,29]. This indicates that emotional impact needs to be explored in future studies.

Stress responses. This study considered acute stress as a function of engagement, distress, and worry. A person being cyberbullied was predicted to have lower task engagement, higher distress, and higher worry than a person who was not bullied. Our research outcomes demonstrated stress due to social exclusion, as evidenced by a lower level of task engagement and an increase in distress only. The resulting analysis did not show any significant effect for worry. However, stress due to verbal harassment was observed, as explained by increases in distress. According to a study by Menesini, Nocentini, Palladino, Frisén, Berne, Ortega-Ruiz, Calmaestra, Scheithauer, Schultze-Krumbholz, Luik, Naruskov, Blaya, Berthaud, and Smith [13], almost 25\% of the participants were not worried if they were being cyberbullied. This finding links the failure to observe worry during social exclusion session to individual differences. On the other hand, impolite comments induced higher worry than social exclusion while impolite comments increases engagement. Up to our knowledge, No previous study compared between verbal harassment and social exclusion. However, observing stress in general terms is consistent with a study of acute stress by Veenstra et al. [102], who have reported that being bullied increases the level of stress. Waisglass [103] has reported that bullying can lead to chronic stress. However, being cyberbullied increases the level of distress [17]. The findings of this study confirm the correlation between stress and cyberbullying.

Coping responses. This exploratory hypothesis evaluated how individuals would cope with being cyberbullied. Being cyberbullied was expected to decrease task-focused coping, increase emotion-focused coping, and increase the level of avoidance. This hypothesis was partially supported. However, the literature indicates a mixed view of the coping strategy. Most cyberbullied individuals cope with cyberbullying by ignoring the situation [54,104]. However, Lazarus and Folkman [66] have indicated that coping strategies used by children faced with many stressors depend mainly on which strategy is adopted. However, any coping strategy adopted depends on the victim's personality but, in general, has been found to reduce the negative effect of stressors [105]. There are differences between aggressive and passive cyberbullying victims in terms of the coping strategy used [70]. Machackova et al. [106] reported that cyberbullying victims use many problem-focused coping strategies except for avoidance strategies. Victims also tend to seek an active solution. The more prolonged ongoing harassment online, the more likely it is to cause more harm than infrequent online harassment [107]. Technological coping strategies, such as blocking the aggressor, were generally effective popular and considered effective [106]. Such coping strategies have been categorized under avoidance coping type. Some studies indicated that bullying activities in collectivist cultures like India and China might lead to intense emotional distress that induces toxic behaviors such as mistrust [108]. However, such actions can be alleviated if appropriate psychological support like friendships is used. Some studies indicated that bullying is not always harmful, as it might sometimes lead to improvements in performance and creativity [108-111].

Verbal harassment through impolite comments vs. social exclusion. Verbal harassment through impolite comments, compared with social exclusion, increases NA, engagement, and worry. Distress showed significant differences, and verbal harassment was found to be more distressing than social exclusion. This result indicates that verbal harassment induces negative emotions and increases distress and worry. This finding is consistent with those of Pieschl, Kuhlmann, and Porsch [30], who have observed that harassment is more distressing than social exclusion. Distress varies between bullying and cyberbullying [112]. In line with the findings of Otten and Jonas [81] verbal harassment has a more intense emotional impact. As indicated by Lazarus [113], active coping is more prevalent during negative emotional encounters [80]. This suggests that active coping is more likely to regulate emotional consequences. Self-evaluations capacity allows individuals to evaluate their behaviors and 
decide whether they hold or not hold responsibility for the action taken [113]. Thus, experiencing verbal harassment might need to be assessed as a cognitive skill. Otten and Jonas [81] suggest that cognitive resources required to regulate behavioral and emotional consequences are more likely during negative emotions.

Menesini, Nocentini, Palladino, Frisén, Berne, Ortega-Ruiz, Calmaestra, Scheithauer, Schultze-Krumbholz, Luik, Naruskov, Blaya, Berthaud, and Smith [13], indicated that although publicity might not be a factor that influences cyberbullying through experimental studies, it cannot be ruled out. They have also indicated that publicity is indirectly relevant to the cyberbullying definition. Publicity has been considered to be one of the main cyberbullying factors [29]. Slonje and Smith [16] have stated that "as the number of people participating online increases, the severity of cyberbullying increases." Pieschl et al. [114] and Sticca and Perren [17] have indicated that public cyberbullying is more stressful than private cyberbullying.

To our knowledge, no previous studies have used the DSSQ-3 or CITS instruments to study cyberbullying. The key strength of this approach is that both instruments can be used to study the stress and coping states, thus facilitating measurement of the self-reported stress responses and coping strategies after each experimental session. The findings of this experimental study must be interpreted with caution, owing to the small sample size. Other limitations preventing the generalization of the results are that the study was performed in a single institution, with psychology students in an introductory course (aged 18-22 years). Some of the statistical findings in this study might be a result of limited statistical power because of the small sample size $(n \mathrm{~N}=29)$. A second limitation is that the study relied on a mixture of hypothetical scenarios, thus potentially limiting the validity of our results. We used laboratory settings designed to stimulate cyberbullying. In real-life scenarios, cyberbullying acts are not subject to laboratory ethical restrictions. Previous studies using self-reporting have indicated sensitivity to cyberbullying publicity [29]. This study also did not consider gender differences. Future cyberbullying research should investigate the effects of age and gender. Finally, this study evaluated only two types of cyberbullying. Future research should examine other types of cyberbullying (e.g., cyberstalking).

As government and state administrators are acting to combat cyberbullying. The possible implication of this study might help. It is essential to be aware of the serious impact of cyberbullying on victims and prepare the appropriate intervention mechanism. Young generations rely heavily on technology where it is common to encounter cyberbullying acts. Although intervention techniques and programs to prevent cyberbullying are in their infancy, it is not currently clear what technologies and programs will be effective in reducing cyberbullying. This study shows that cyberbullying can have serious negative emotional impacts. However, the degree of reacting toward the type of cyberbullying vary based on individualistic characteristics and culture. This study might also help to find mechanisms that may help detect exposure to cyberbullying. As cyberbullying incidents become more frequent, it is crucial to realize the negative impacts and intervene correctly. Effective coping mechanisms require education and training programs. Those training programs might provide coping skills and social support for cyberbullying victims to alleviate distress [115].

In summary, this experimental study provides insight into the temporal reactions to cyberbullying in terms of being verbally abused or excluded. Experiencing cyberbullying affects victims' wellbeing. Regarding the question of whether verbal harassment or social exclusion is more severe, participants rated verbal harassment as more critical. Given this finding, future research should further investigate and assess the effects of cyberbullying by using different experimental settings and different age groups. Hartgerink, van Beest, Wicherts, and Williams [40], while studying school shootings, have found a link between ostracism and revenge. This study might be useful for anti-cyberbullying campaigns in educational and professional environments. However, Berne et al. [116] have indicated that students are willing to support and participate in anti-cyberbullying campaigns. The mechanism provided herein might be used to educate younger people on the two critical types of cyberbullying. 
Author Contributions: Formal analysis, A.A., W.K. and P.H.; Investigation, A.A.; Methodology, A.A., W.K. and P.H.; Writing—original draft, A.A.; Writing-review and editing, W.K., T.T.H.W. and P.H. All authors have read and agreed to the published version of the manuscript.

Funding: This research received no external funding.

Acknowledgments: This article is based on a dissertation submitted by AA in partial fulfillment of the requirements for a Ph.D., University of Central Florida [117].

Conflicts of Interest: The authors declare no conflict of interest.

Ethics Statement : All participants provided informed consent in accordance with the Declaration of Helsinki. The study was approved by the Institutional Review Board of University of Central Florida.

\section{References}

1. Burk, F.L. Teasing and Bullying. Pedagog. Semin. 1897, 4, 336-371. [CrossRef]

2. Olweus, D. Aggression in the Schools: Bullies and Whipping Boys; Hemisphere: Oxford, UK, 1978. [CrossRef]

3. Farley, S.; Coyne, I.; Sprigg, C.; Axtell, C.; Subramanian, G. Exploring the impact of workplace cyberbullying on trainee doctors. Med. Educ. 2015, 49, 436-443. [CrossRef] [PubMed]

4. Gardner, D.; O’Driscoll, M.; Cooper-Thomas, D.H.; Roche, M.; Bentley, T.; Catley, B.; Teo, T.S.; Trenberth, L. Predictors of Workplace Bullying and Cyber-Bullying in New Zealand. Int. J. Environ. Res. Public Health 2016, 13, 448. [CrossRef]

5. Navarro, R.; Yubero, S.; Larrañaga, E. Cyberbullying Across the Globe: Gender, Family, and Mental Health; Springer Science + Business Media: New York, NY, USA, 2015. [CrossRef]

6. Willard, N. Cyber Savvy: Embracing Digital Safety and Civility; Corwin: Thousand Oaks, CA, USA, $2011 ;$ p. 176.

7. Servance, R.L. Cyberbullying, cyber-harassment, and the conflict between schools and the first amendment. Wisconsin Law Rev. 2003, 2003, 1213-1244.

8. Hazelwood, S.D.; Koon-Magnin, S. Cyber stalking and cyber harassment legislation in the United States: A qualitative analysis. Int. J. Cyber Criminol. 2013, 7, 155-168.

9. Moy, J. Beyond 'the schoolhouse gates' and into the virtual playground: Moderating student cyberbullying and cyberharassment after Morse v. Frederick. Hastings Const. Law Q. 2009, 37, 565-590.

10. Berger, K. Update on bullying at school: Science forgotten? Dev. Rev. 2007, 27, 90-126. [CrossRef]

11. Gendreau, P.L.; Archer, J. Subtypes of Aggression in Humans and Animals. In Developmental Origins of Aggression; Tremblay, R.E., Hartup, W.W., Archer, J., Tremblay, R.E., Hartup, W.W., Archer, J., Eds.; Guilford Press: New York, NY, USA, 2005; pp. 25-46. [CrossRef]

12. Johnson, J.M. The impact of cyber bullying: A new type of relational aggression. In Proceedings of the American Counseling Association Annual Conference and Exposition, Charlotte, NC, USA, 19-23 March 2009.

13. Menesini, E.; Nocentini, A.; Palladino, B.E.; Frisén, A.; Berne, S.; Ortega-Ruiz, R.; Calmaestra, J.; Scheithauer, H.; Schultze-Krumbholz, A.; Luik, P.; et al. Cyberbullying Definition Among Adolescents: A Comparison Across Six European Countries. Cyberpsychol. Behav. Soc. Netw. 2012, 15, 455-463. [CrossRef]

14. Nowosad, I.; Miłkowska, G.; Bąbka, J.; Cernova, E.; Daniela, L.; Döbert, H.; Havigerova, J.M.; Kalnina, D.; Karikova, S.; Kobylecka, E. A Child in School Setting; Wydawnictwo Adam Marszałek: Torun, Poland, 2011.

15. Slaninova, G.; Haviger, J.; Novotna, L.; Sochorova, P.; Vackova, M. Relationship between cyberbullying and readiness for aggressive behavior in middle adolescence. Procedia Soc. Behav. Sci. 2011, 29, 567-573. [CrossRef]

16. Slonje, R.; Smith, P.K. Cyberbullying: Another main type of bullying? Scand. J. Psychol. 2008, 49, 147-154. [CrossRef]

17. Sticca, F.; Perren, S. Is Cyberbullying Worse than Traditional Bullying? Examining the Differential Roles of Medium, Publicity, and Anonymity for the Perceived Severity of Bullying. J. Youth Adolesc. 2013, 42, 739-750. [CrossRef]

18. Li, Q. Bullying in the new playground: Research into cyberbullying and cyber victimisation. Australas. J. Educ. Technol. 2007, 23, 435-454. [CrossRef]

19. Dooley, J.; Shaw, T.; Cross, D. The association between the mental health and behavioural problems of students and their reactions to cyber-victimization. Eur. J. Dev. Psychol. 2012, 9, 275-289. [CrossRef] 
20. Kowalski, R.M.; Giumetti, G.W.; Schroeder, A.N.; Lattanner, M.R. Bullying in the digital age: A critical review and meta-analysis of cyberbullying research among youth. Psychol. Bull. 2014, 140, 1073-1137. [CrossRef] [PubMed]

21. Elgar, F.J.; Napoletano, A.; Saul, G.; Dirks, M.A.; Craig, W.; Poteat, V.P.; Holt, M.; Koenig, B.W. Cyberbullying victimization and mental health in adolescents and the moderating role of family dinners. JAMA Pediatrics 2014, 168, 1015-1022. [CrossRef]

22. Wang, W.; Xie, X.; Wang, X.; Lei, L.; Hu, Q.; Jiang, S. Cyberbullying and depression among Chinese college students: A moderated mediation model of social anxiety and neuroticism. J. Affect. Disord. 2019, 256, 54-61. [CrossRef]

23. Nansel, T.R.; Craig, W.; Overpeck, M.D.; Saluja, G.; Ruan, W. Cross-national consistency in the relationship between bullying behaviors and psychosocial adjustment. Arch. Pediatrics Adolesc. Med. 2004, 158, 730-736. [CrossRef]

24. Jawaid, A.; Riby, D.M.; Owens, J.; White, S.W.; Tarar, T.; Schulz, P.E. 'Too withdrawn' or 'too friendly': Considering social vulnerability in two neuro-developmental disorders. J. Intellect. Disabil. Res. 2012, 56, 335-350. [CrossRef]

25. Liorent, V.J.; Ortega-Ruiz, R.; Zych, I. Bullying and cyberbullying in minorities: Are they more vulnerable than the majority group? Front. Psychol. 2016, 7. [CrossRef]

26. Ybarra, M.L.; Mitchell, K.J. Prevalence and Frequency of Internet Harassment Instigation: Implications for Adolescent Health. J. Adolesc. Health 2007, 41, 189-195. [CrossRef]

27. König, A.; Gollwitzer, M.; Steffgen, G. Cyberbullying as an Act of Revenge? Aust. J. Guid. Couns. 2012, 20, 210-224. [CrossRef]

28. Ybarra, M.L.; Mitchell, K.J. Youth engaging in online harassment: Associations with caregiver-child relationships, Internet use, and personal characteristics. J. Adolesc. 2004, 27, 319-336. [CrossRef] [PubMed]

29. Dooley, J.; Pyżalski, J.; Cross, D. Cyberbullying versus face-to-face bullying: A theoretical and conceptual review. Z. Für Psychol. J. Psychol. 2009, 217, 182-188. [CrossRef]

30. Pieschl, S.; Kuhlmann, C.; Porsch, T. Beware of Publicity! Perceived Distress of Negative Cyber Incidents and Implications for Defining Cyberbullying. J. Sch. Violence 2015, 14, 111-132. [CrossRef]

31. Vasquez, E.A.; William, P.C.; Brad, B.J.; Nicholas, K.J.D.; Miller, N. Lashing Out after Stewing over Public Insults: The Effects of Public Provocation, Provocation Intensity, and Rumination on Triggered Displaced Aggression. Aggress. Behav. 2013, 39, 13-29. [CrossRef]

32. Otten, M.; Mann, L.; van Berkum, J.J.A.; Jonas, K.J. No laughing matter: How the presence of laughing witnesses changes the perception of insults. Soc. Neurosci. 2016, 12, 182-193. [CrossRef]

33. Williams, K.D.; Cheung, C.K.; Choi, W. Cyberostracism: Effects of being ignored over the Internet. J. Pers. Soc. Psychol. 2000, 79, 748-762. [CrossRef]

34. Young, E.L.; Nelson, D.A.; Hottle, A.B.; Warburton, B.; Young, B.K. Relational aggression in schools: Information for educators. East West Highw. Suite 2010, 402, 24.

35. Williams, K.; Jarvis, B. Cyberball: A program for use in research on interpersonal ostracism and acceptance. Behav. Res. Methods 2006, 38, 174-180. [CrossRef]

36. Faulkner, S.; Williams, K.; Sherman, B.; Williams, E. The "silent treatment": Its incidence and impact. In Proceedings of the 69th Annual Meeting of the Midwestern Psychological Association, Chicago, IL, USA, 8-10 May 1997.

37. Alhujailli, A.; Karwowski, W. Emotional and Stress Responses to Cyberbullying. In Proceedings of the Advances in Design for Inclusion, Orlando, FL, USA, 21-25 July 2018; pp. 33-43.

38. Chan, H.C.; Wong, D.S.W. Traditional school bullying and cyberbullying in Chinese societies: Prevalence and a review of the whole-school intervention approach. Aggress. Violent Behav. 2015, 23, 98-108. [CrossRef]

39. Guo, S. A Meta-Analysis of The Predictors of Cyberbullying Perpetration and Victimization. Psychol. Sch. 2016, 53, 432-453. [CrossRef]

40. Hartgerink, C.H.J.; van Beest, I.; Wicherts, J.M.; Williams, K.D. The Ordinal Effects of Ostracism: A Meta-Analysis of 120 Cyberball Studies. PLoS ONE 2015, 10, e0127002. [CrossRef]

41. Romero-Canyas, R.; Downey, G. Rejection Sensitivity as a Predictor of Affective and Behavioral Responses to Interpersonal Stress: A Defensive Motivational System. In The Social Outcast: Ostracism, Social Exclusion, Rejection, and Bullying; Psychology Press: New York, NY, USA, 2005; pp. 131-154. [CrossRef] 
42. Reijntjes, A.; Stegge, H.; Meerum Terwogt, M. Children's coping with peer rejection: The role of depressive symptoms, social competence, and gender. Infant Child Dev. 2006, 15, 89-107. [CrossRef]

43. Steele, A.K. Facebook's effect on emotional reactivity to in-lab peer feedback manipulations. Ph.D. Thesis, University of Texas at Austin, Austin, TX, USA, 2016.

44. Joseph, B.W.; Kyle, P.D.A. The Impacts of Emoticons on Message Interpretation in Computer-Mediated Communication. Soc. Sci. Comput. Rev. 2001, 19, 324-347. [CrossRef]

45. Kleinginna, P.R.; Kleinginna, A.M. A categorized list of emotion definitions, with suggestions for a consensual definition. Motiv. Emot. 1981, 5, 345-379. [CrossRef]

46. Brave, S.; Nass, C. Emotion in human-computer interaction. In The Human-Computer Interaction Handbook, 1st ed.; Julie, A.J., Andrew, S., Eds.; L. Erlbaum Associates Inc.: Hillsdale, NJ, USA, 2003; pp. 81-96.

47. Watson, D.; Clark, L.A. Negative affectivity: The disposition to experience aversive emotional states. Psychol. Bull. 1984, 96, 465-490. [CrossRef]

48. Watson, D.; Clark, L.A.; Tellegen, A. Development and validation of brief measures of positive and negative affect: The PANAS scales. J. Pers. Soc. Psychol. 1988, 54, 1063-1070. [CrossRef]

49. Hinduja, S.; Patchin, J.W. Bullying, Cyberbullying, and Suicide. Arch. Suicide Res. 2010, 14, $206-221$. [CrossRef]

50. Gemzøe Mikkelsen, E.; Einarsen, S. Relationships between exposure to bullying at work and psychological and psychosomatic health complaints: The role of state negative affectivity and generalized self-efficacy. Scand. J. Psychol. 2008, 43, 397-405. [CrossRef]

51. George, J.M. Trait and state affect. In Individual Differences and Behavior in Organizations; Murphy, K.R., Ed.; Jossey-Bass Publishers: San Francisco, CA, USA, 1996; Volume 1, pp. 145-171.

52. Lazarus, R.S.; Folkman, S. Stress, Appraisal, and Coping; Springer: New York, NY, USA, 1984.

53. Jang, H.; Song, J.; Kim, R. Does the offline bully-victimization influence cyberbullying behavior among youths? Application of General Strain Theory. Comput. Hum. Behav. 2014, 31, 85-93. [CrossRef]

54. Völlink, T.; Bolman Catherine, A.W.; Dehue, F.; Jacobs Niels, C.L. Coping with Cyberbullying: Differences Between Victims, Bully-victims and Children not Involved in Bullying. J. Community Appl. Soc. Psychol. 2013, 23, 7-24. [CrossRef]

55. Williams, K.D.; Carter-Sowell, A.R. Marginalization through social ostracism: Effects of being ignored and excluded. In Coping with Minority Status: Responses to Exclusion and Inclusion; Cambridge University Press: New York, NY, USA, 2009; pp. 104-122. [CrossRef]

56. Giumetti, G.W.; Hatfield, A.L.; Scisco, J.L.; Schroeder, A.N.; Muth, E.R.; Kowalski, R.M. What a rude e-mail! Examining the differential effects of incivility versus support on mood, energy, engagement, and performance in an online context. J. Occup. Health Psychol. 2013, 18, 297-309. [CrossRef]

57. Szalma, J.L.; Hancock, P.A. Noise effects on human performance: A meta-analytic synthesis. Psychol. Bull. 2011, 137, 682-707. [CrossRef] [PubMed]

58. Michelle, K.; Duffy, A.; Daniel, C.; Ganster, A.; Milan Pagon, A. Social Undermining in the Workplace. Acad. Manag. J. 2002. [CrossRef]

59. Mohr, G.; Wolfram, H.-J.; Mohr, G.; Wolfram, H.J. Stress among managers: The importance of dynamic tasks, predictability, and social support in unpredictable times. J. Occup. Health Psychol. 2010, 15, 167-179. [CrossRef]

60. Hancock, P.A.; Warm, J.S. A Dynamic Model of Stress and Sustained Attention. J. Hum. Perform. Extrem. Environ. 2003, 7, 15-28. [CrossRef]

61. Matthews, G.; Szalma, J.; Panganiban, A.R.; Neubauer, C.; Warm, J.S. Profiling task stress with the Dundee stress state questionnaire. In Psychology of Stress: New Research; Leandro Cavalcanti, S.A., Ed.; Nova Science Pub. Inc.: Hauppauge, NY, USA, 2013; Volume 1, pp. 49-90.

62. Hobfoll, S.E. The Influence of Culture, Community, and the Nested-Self in the Stress Process: Advancing Conservation of Resources Theory. Appl. Psychol. 2001, 50, 337-421. [CrossRef]

63. Aldwin, C.M. Stress, Coping, and Development: An Integrative Perspective, 2nd ed.; Guilford Press: New York, NY, USA, 2007.

64. Mariana, K.; Fernando, P.; Cristina, Q.; Pedro, S. Stress Appraisal, Coping, and Work Engagement among Police Recruits: An Exploratory Study. Psychol. Rep. 2014, 114, 635-646. [CrossRef]

65. Lazarus, R.S. Emotion and Adaptation; Oxford University Press: New York, NY, USA, 1991. 
66. Lazarus, R.S.; Folkman, S. Transactional theory and research on emotions and coping. Eur. J. Personal. 1987, 1, 141-169. [CrossRef]

67. Lodge, J.; Frydenberg, E. Cyber-Bullying in Australian Schools: Profiles of Adolescent Coping and Insights for School Practitioners. Aust. Educ. Dev. Psychol. 2007, 24, 45-58. [CrossRef]

68. Raskauskas, J.; Huynh, A. The process of coping with cyberbullying: A systematic review. Aggress. Violent Behav. 2015, 23, 118-125. [CrossRef]

69. Catterson, J.; Hunter, S.C. Cognitive mediators of the effect of peer victimization on loneliness. Br. J. Educ. Psychol. 2010, 80, 403-416. [CrossRef] [PubMed]

70. Chan, H.C.; Wong, D.S.W. Coping with cyberbullying victimization: An exploratory study of Chinese adolescents in Hong Kong. Int. J. Law Crime Justice 2017, 50, 71-82. [CrossRef]

71. Baumeister, R.F.; Leary, M.R. The need to belong: Desire for interpersonal attachments as a fundamental human motivation. Psychol. Bull. 1995, 117, 497-529. [CrossRef]

72. van Beest, I.; Williams, K.D. When inclusion costs and ostracism pays, ostracism still hurts. J. Pers. Soc. Psychol. 2006, 91, 918-928. [CrossRef]

73. Williams, K.D. Ostracism. Annu. Review Psychol. 2007, 58, 425-452. [CrossRef]

74. Ruggieri, S.; Bendixen, M.; Gabriel, U.; Alsaker, F. Cyberball: The impact of ostracism on the well-being of early adolescents. Swiss J. Psychol. 2013, 72, 103-109. [CrossRef]

75. Eisenberger, N.I. Identifying the Neural Correlates Underlying Social Pain: Implications for Developmental Processes. Hum. Dev. 2006, 49, 273-293. [CrossRef]

76. Williams, K.D.; Govan, C.L.; Croker, V.; Tynan, D.; Cruickshank, M.; Lam, A. Investigations into differences between social- and cyberostracism. Group Dyn. Theory Res. Pract. 2002, 6, 65-77. [CrossRef]

77. Karwoski, J.B.; Summers, R.W. Conflict, Aggression, and Cyberbullying. In Social Psychology: How Other People Influence Our Thoughts and Actions [2 Volumes]; Summers, R.W., Ed.; Greenwood: Santa Barbara, CA, USA, 2016; pp. 161-186.

78. Raskauskas, J. Text-Bullying: Associations With Traditional Bullying and Depression Among New Zealand Adolescents. J. Sch. Violence 2009, 9, 74-97. [CrossRef]

79. Coolidge, F.L.; DenBoer, J.W.; Segal, D.L. Personality and neuropsychological correlates of bullying behavior. Personal. Individ. Differ. 2004, 36, 1559-1569. [CrossRef]

80. Otten, M.; Jonas, K.J. Humiliation as an intense emotional experience: Evidence from the electroencephalogram. Soc. Neurosci. 2014, 9, 23-35. [CrossRef]

81. Gendron, M.; Barrett, L.F. Reconstructing the Past: A Century of Ideas About Emotion in Psychology. Emot. Rev. 2009, 1, 316-339. [CrossRef] [PubMed]

82. Kern, D.M. The Evolution of Social Pain: Understanding the Neural Network of Social Ostracism through Electroencephalography; Honors Projects Illinois Wesleyan University: Bloomington, IL, USA, 2011.

83. Kassner, M.P.; Wesselmann, E.D.; Law, A.T.; Williams, K.D. Virtually Ostracized: Studying Ostracism in Immersive Virtual Environments. Cyberpsychol. Behav. Soc. Netw. 2012, 15, 399-403. [CrossRef]

84. Cohen, G.; Prinstein, M.J. Peer contagion of aggression and health risk behavior among adolescent males: An experimental investigation of effects on public conduct and private attitudes. Child Dev. 2006, 77, 967-983. [PubMed]

85. Whitaker, V. Frontal Lobe Theta Activity in Socially Ostracized Individuals: Understanding Social Ostracism through EEG; Honors Projects Illinois Wesleyan University: Bloomington, IL, USA, 2014.

86. Gardner, W.L.; Pickett, C.L.; Brewer, M.B. Social Exclusion and Selective Memory: How the Need to belong Influences Memory for Social Events. Personal. Soc. Psychol. Bull. 2000, 26, 486-496. [CrossRef]

87. Wolf, W.; Levordashka, A.; Ruff, J.R.; Kraaijeveld, S.; Lueckmann, J.-M.; Williams, K.D. Ostracism Online: A social media ostracism paradigm. Behav. Res. Methods 2015, 47, 361-373. [CrossRef]

88. Tran, V. Positive Affect Negative Affect Scale (PANAS). In Encyclopedia of Behavioral Medicine; Gellman, M.D., Turner, J.R., Eds.; Springer: New York, NY, USA, 2013; pp. 1508-1509. [CrossRef]

89. Matthews, G.; Joyner, L.; Gilliland, K.; Campbell, S.; Falconer, S.; Huggins, J. Validation of a comprehensive stress state questionnaire: Towards a state big three. Personal. Psychol. Eur. 1999, 7, 335-350.

90. Matthews, G.; Emo, A.; Funke, G. A short version of the Dundee Stress State Questionnaire. In Proceedings of the Twelfth Meeting of the International Society for the Study of Individual Differences, Adelaide, Australia, July 2005. 
91. Matthews, G.; Campbell, S.E. Task-Induced Stress and Individual Differences in Coping. Proc. Hum. Factors Ergon. Soc. Annu. Meet. 1998, 42, 821-825. [CrossRef]

92. Zadro, L.; Williams, K.D.; Richardson, R. How low can you go? Ostracism by a computer is sufficient to lower self-reported levels of belonging, control, self-esteem, and meaningful existence. J. Exp. Soc. Psychol. 2004, 40, 560-567. [CrossRef]

93. Rosenthal, R.; Rosnow, R.L. Artifacts in Behavioral Research: Robert Rosenthal and Ralph L. Rosnow's Classic Books; Oxford University Press: New York, NY, USA, 2009. [CrossRef]

94. Wellsby, M.; Siakaluk, P.; Pexman, P.; Owen, W. Some Insults are Easier to Detect: The Embodied Insult Detection Effect. Front. Psychol. 2009, 1. [CrossRef]

95. Van Berkum, J.J.A.; Koornneef, A.W.; Otten, M.; Nieuwland, M.S. Establishing reference in language comprehension: An electrophysiological perspective. Brain Res. 2007, 1146, 158-171. [CrossRef] [PubMed]

96. Siakaluk, P.D.; Pexman, P.M.; Dalrymple, H.-A.R.; Stearns, J.; Owen, W.J. Some insults are more difficult to ignore: The embodied insult Stroop effect. Lang. Cogn. Process. 2011, 26, 1266-1294. [CrossRef]

97. Guillory, J.; Spiegel, J.; Drislane, M.; Weiss, B.; Donner, W.; Hancock, J. Upset now?: Emotion contagion in distributed groups. In Proceedings of the SIGCHI Conference on Human Factors in Computing Systems, Vancouver, BC, Canada, May 2011; pp. 745-748.

98. Chung, C.; Pennebaker, J. The Psychological Functions of Function Words. In Social Communication; Fiedler, K., Fiedler, K., Eds.; Psychology Press: New York, NY, USA, 2007; pp. 343-359.

99. Wayne, H.; Iain, C. Understanding individual experiences of cyberbullying encountered through work. Int. J. Organ. Theory Behav. 2014, 17, 163-192. [CrossRef]

100. Wright, M.F. Youths and Cyberbullying: Description, Theories, and Recommendations. In Handbook of Research on Human Development in the Digital Age; Bryan, V., Musgrove, A., Powers, J., Eds.; IGI Global: Hershey, PA, USA, 2017. [CrossRef]

101. Garaigordobil, M.; Machimbarrena, J.M. Victimization and perpetration of bullying/cyberbullying: Connections with emotional and behavioral problems and childhood stress. Psychosoc. Interv. 2019, 28, 67-73. [CrossRef]

102. Veenstra, R.; Lindenberg, S.; Oldehinkel, A.J.; De Winter, A.F.; Verhulst, F.C.; Ormel, J. Bullying and Victimization in Elementary Schools: A Comparison of Bullies, Victims, Bully/Victims, and Uninvolved Preadolescents. Dev. Psychol. 2005, 41, 672-682. [CrossRef]

103. Waisglass, N. The Lasting Effects of Cyber Bullying on Well-Being; Brescia University College: London, ON, Canada, 2017.

104. Šléglová, V.; Cerna, A. Cyberbullying in adolescent victims: Perception and coping. Cyberpsychol. J. Psychosoc. Res. Cyberspace 2011, 5.

105. Hampel, P.; Manhal, S.; Hayer, T. Direct and Relational Bullying Among Children and Adolescents: Coping and Psychological Adjustment. Sch. Psychol. Int. 2009, 30, 474-490. [CrossRef]

106. Machackova, H.; Cerna, A.; Sevcikova, A.; Dedkova, L.; Daneback, K. Effectiveness of coping strategies for victims of cyberbullying. Cyberpsychol. J. Psychosoc. Res. Cyberspace 2013, 7. [CrossRef]

107. Tokunaga, R.S. Following you home from school: A critical review and synthesis of research on cyberbullying victimization. Comput. Hum. Behav. 2010, 26, 277-287. [CrossRef]

108. Agarwal Upasna, A.; Rai, A. Exploring bullying among Indian managers: A grounded theory approach. J. Asia Bus. Stud. 2019, 13, 588-611. [CrossRef]

109. Bulutlar, F.; Öz, E.Ü. The Effects of Ethical Climates on Bullying Behaviour in the Workplace. J. Bus. Ethics 2009, 86, 273-295. [CrossRef]

110. Cooper-Thomas, H.; Gardner, D.; O’Driscoll, M.; Catley, B.; Bentley, T.; Trenberth, L. Neutralizing workplace bullying: The buffering effects of contextual factors. J. Manag. Psychol. 2013, 28, 384-407. [CrossRef]

111. Samnani, A.-K.; Singh, P.; Ezzedeen, S. Workplace bullying and employee performance: An attributional model. Organ. Psychol. Rev. 2013, 3, 337-359. [CrossRef]

112. Bauman, S.; Newman, M.L. Testing assumptions about cyberbullying: Perceived distress associated with acts of conventional and cyber bullying. Psychol. Violence 2013, 3, 27-38. [CrossRef]

113. Lewis, M. Self-Conscious Emotions. Am. Sci. 1995, 83, 68-78.

114. Pieschl, S.; Porsch, T.; Kahl, T.; Klockenbusch, R. Relevant dimensions of cyberbullying-Results from two experimental studies. J. Appl. Dev. Psychol. 2013, 34, 241-252. [CrossRef] 
115. Zhou, H.; Peng, J.; Wang, D.; Kou, L.; Chen, F.; Ye, M.; Deng, Y.; Yan, J.; Liao, S. Mediating effect of coping styles on the association between psychological capital and psychological distress among Chinese nurses: A cross-sectional study. J. Psychiatr. Ment. Health Nurs. 2017, 24, 114-122. [CrossRef] [PubMed]

116. Berne, S.; Frisén, A.; Oskarsson, J. High school students' suggestions for supporting younger pupils counteract cyberbullying. Scand. J. Psychol. 2019. [CrossRef]

117. Alhujailli, A.M. A Study of EEG Signatures Associated with Emotional and Stress Responses Due to Cyberbullying; University of Central Florida: Orlando, FL, USA, 2018.

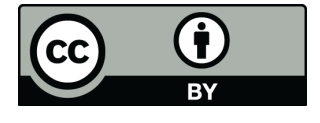

(C) 2020 by the authors. Licensee MDPI, Basel, Switzerland. This article is an open access article distributed under the terms and conditions of the Creative Commons Attribution (CC BY) license (http://creativecommons.org/licenses/by/4.0/). 